\title{
The Development Strategy of E-Commerce Logistics in Beijing
}

\author{
Bingwu Liu, Juntao Li \\ Beijing Wuzi University, Beijing, China \\ Email: ljtletter@126.com
}

Received 8 October 2015; accepted 9 November 2015; published 12 November 2015

Copyright (C 2015 by authors and Scientific Research Publishing Inc.

This work is licensed under the Creative Commons Attribution International License (CC BY). http://creativecommons.org/licenses/by/4.0/

(c) (i) Open Access

\begin{abstract}
"Warehouse explosion phenomenon" of e-commerce, the last one kilometer electricity supplier logistics problems and high cost of logistics and other issues, has become a troubled electricity supplier and logistics companies the biggest problem. Therefore the major commercial enterprises have chosen enterprise logistics operation model according to the different characteristics of their respective enterprises. This paper analyzed the present situation and characteristics of e-commerce logistics in Beijing, and put forward the Countermeasures for the development of ecommerce logistics in Beijing. The countermeasures of the integration development of Beijing, Tianjin and Hebei, e-commerce logistics business model and the policy measures should greatly promote the development the e-commerce in Beijing.
\end{abstract}

\section{Keywords}

Beijing, E-Commerce, Logistics, Countermeasures

\section{Introduction}

National Business to Customer (B2C) sales scale of the top 10 enterprises in the 6 headquarters in Beijing, Beijing e-commerce retail sales reached 25.64 billion Yuan, an increase of $100 \%{ }^{1}$. E-commerce has become an important part of the economic growth mode in Beijing city. As an important link in the process of electronic commerce, logistics plays an important role in the promotion of e-commerce enterprises, and the logistics system is a kind of effective logistics system. Released in early 2012, the ministry of industry and information technology of the electronic commerce development "The Twelfth Five-Year" Plan (hereinafter referred to as the "planning"), by 2015, e-commerce transactions to quadruple will exceed 18 trillion Yuan, and the network retail will reach 3 trillion Yuan.

${ }^{1}$ SCIO of the People’s Republic of China: $\underline{w w w . s c i o . g o v . c n}$ 
With the increase and improvement of service sales, e-commerce logistics model also will be changed, such as return, depot, and sparing parts turnover of links, all in a great test of the current e-commerce company’s logistics system. Domestic large-scale e-commerce company's logistics model is using a variety of logistics model SOP, SOPL, FBP, and LBP, which all improve vendor participant involvement and flexibility.

"Warehouse explosion phenomenon" of e-commerce, the electricity supplier of the last mile of the logistics problems and logistics cost too high, has become the biggest problem of troubled commercial enterprises and logistics enterprises. Therefore the business enterprise has chosen the suitable for their own business logistics operation model according to the different characteristics of their respective enterprises. For B2C enterprises there are more choices of enterprise self logistics way. For example, Jingdong mall and vancl.com hope to obtain express business qualification to help you solve the last mile problem. On the other hand, express delivery companies, such as SF, extend upward through investment in e-commerce sites to share the big cake of e-commerce logistics. There is also a part of the B2C company to take the mixed logistics operation mode of cooperation with the courier company, we have built a logistics center, but its distribution is accomplished through the Third party logistics (3PL), and the distribution of the third party logistics companies to achieve seamless link. And foreign electricity supplier in the settlement of the logistics is to take the form of cooperation with the third party logistics enterprises. Such as size of 250 million in 2011 Euros in German market of electronic business affairs, top ten commercial enterprises such as Amazon, regardless of their own logistics center, almost all through the third party logistics company last mile delivery, showed mature market division of labor and orderly competition ${ }^{2}$.

"Twelfth Five-Year" period, is the construction of "humanistic Beijing, science and technology Beijing, green Beijing” important stage. "Twelfth Five Year” period is an important stage the construction of Humanities Beijing, Science Beijing, and Technology Beijing. Vigorously developing e-commerce, not only is the capital to break through the geographical space and natural resources constraints, to transform the development momentum, promote industrial restructuring and upgrading, stimulating consumption of strategic initiatives, but also to enhance urban services, ease traffic, improve the quality of life, and create new business and employment patterns of important support. As the core of the rapid development of e-commerce, e-commerce logistics construction is the main problem of the development of e-commerce logistics in Beijing City, such as the construction and operation mode is not clear, e-commerce logistics policy is missing, so it is necessary to carry out the development of e-commerce logistics development in Beijing city.

\section{Domestic and Foreign Electronic Commerce Logistics Development Present Situation Analysis}

\subsection{Foreign E-Commerce Logistics Development Status Analysis}

For the development of electric business logistics, the logistics system of Japan and Europe and the United States as an example.

Japan's logistics modernization degree is high and becomes one of the pillar industries in Japan. The Japanese government proposed trilateral logistics information platform, and provides free information services to the enterprises [1]. In Japan, the next line of business entities under the network is developed, and e-commerce distribution system is to spread across the country's convenience stores as a base. In order to enhance the consumer shopping experience and market competitiveness, YAHOO Japan joint entity store to put forward 2 hours of online shopping service.

Europe and the United States of logistics and distribution system is complete and formal. Especially in recent years, large third-party logistics company, the different regions the number of Internet users, often can click shopping on the day or days can receive the products they need. Thanks to the history of Europe and the United States for nearly a hundred years of storage and transportation system.

At present, the United States in the top 50 of all kinds of electronic business enterprises, $90 \%$ of which are in various forms to provide free shipping services, and become the new characteristics of the development of e-commerce ${ }^{3}$. At the same time, in order to effectively solve the huge number of network orders shopping season, difficult to deliver goods to the difficulties, eBay, Amazon, WAL-MART and other major electricity suppliers and business enterprises are increasing the intensity of the line distribution. Who with powerful logistics

${ }^{2}$ E-commerce: http://www.zk365.com/xypd/dsdt/966.asp

${ }^{3}$ Cnii.com.cn: http://www.cnii.com.cn/internetnews/2013-12/09/content_1267775.htm 
and distribution functions will become the major e-commerce companies in the United States the direction of development.

Overall, foreign business companies such as Amazon and other major take the form of logistics outsourcing, because foreign logistics industry is relatively developed, logistics system is relatively perfect, and technology is advanced. Electricity suppliers can be assured that the logistics business outsourcing to the third party, so they are focused on the development of the main business and core business. This can reduce investment and business risks, at the same time, make full use of the advantages of professional logistics companies and save logistics costs.

\subsection{Analysis of the Current Situation of the Development of E-Commerce Logistics in Beijing}

Beijing has gathered the development of electronic business logistics information technology, business logistics, financial talent, international resource advantages, such as docking initially formed e-commerce industry cluster. According to the city Bureau of statistics data show, in 2010 Beijing e-commerce transaction volume is about 400 billion yuan, "Eleventh Five Year" period, average annual growth of $45 \%$, third-party e-commerce platform turnover to 260 billion yuan. Beijing e-commerce enterprises accounted for pabout $9 \%$ of the total amount of the country. E-commerce has become an important part of the economic growth mode in Beijing, and its development mode is characterized by the following features:

\subsubsection{E-commerce Technology and Mode of Innovation to Accelerate the Pace}

Beijing is the core node of the next generation Internet demonstration project and the national triple play pilot cities. The pilot construction of wireless city will provide a competitive application environment support for further strengthening the development of e-commerce. Beijing aims to actively promote the e-commerce and cloud calculation, Internet of things technology application, started with "Xiangyun" project is the core of the national cloud computing pilot construction projects and networking in urban grid management, video surveillance, intelligent transportation, food traceability, water quality testing, should be used in the national leading level.

\subsubsection{Electric Business Enterprise Distribution System Is Constantly Improving}

Beijing e-commerce distribution system construction continues to make a breakthrough, logistics and distribution system of the overall service capacity of the country's leading. In terms of logistics services, the first is to carry out the construction of urban distribution system, focus on building the city 100 - joint distribution project, and achieve the efficient integration of the logistics courier industry personnel, network and other terminal resources.

\subsubsection{The Leading Enterprises in Industry Alliance Initial Shape}

At present, the national B2C shopping website ranking of the top 10 enterprises, there are 6 headquarters in Zhongguancun. In order to enhance the level of service of e-commerce and modern logistics industry in Beijing, the Zhongguancun e-commerce and modern logistics industry alliance has been established in Beijing. The Union will seize the capital and the country in the electronic commerce, logistics service system, industry optimization, supply chain coordination, financing services, logistics information and other urgent needs, the use of 3 years to 5 years, to promote the implementation of a number of Beijing e-commerce logistics integration application demonstration project.

With the rapid development of e-commerce and the increasing demand of industry logistics, the mode of small batch and high frequency operation will become the developing trend of modern logistics business, and the rapid response capability of logistics is gradually improved. With the rapid development of e-commerce, the problem is exposed, the main problems include: 1 Lack of systematic scientific planning and overall construction mode scheme; 2) At present, the logistics system is not fully adapted to the characteristics of e-commerce industry, because of the use of traditional logistics system and equipment; 3 ) electricity business enterprise logistics intelligent level is low.

\section{Analysis on the Characteristics of E-Commerce Logistics in Beijing City}

As an international metropolis, Beijing has become the basis for most electricity suppliers. According to the 
city’s Commerce Commission statistics, the scale biggest nine proprietary B2C enterprises have 5 Beijing enterprises, accounting for $67.1 \%$ of the transaction size. Such a large amount of electricity supplier B2C enterprise determines the electricity supplier in Beijing electricity supplier in the country has a large range of guidance. E-commerce has become a new engine driving the growth of consumption in Beijing. Statistics Department statistics, in 2013 Beijing social retail sales of consumer goods amounted to 837.51 billion yuan, which realize online retail sales 92.68 billion yuan, $44.3 \%$ growth, accounted for $11.1 \%$ of the city's retail sales of social consumer goods, contribution to the increment of social zero turnover reached $42.4 \%$ is expected in the new year, and strive to achieve net retail sales of 11 billion yuan, the proportion of social zero turnover of around $12 \%{ }^{4}$. Based on the 2013 full year of e-commerce in Beijing business contribution, in 2014, Beijing electricity suppliers will also usher in a new trend in the brand, consumption, logistics, distribution and so on.

\subsection{Cross-Border E-Commerce Logistics Service Demand}

At present, China's cross-border e-commerce development rapidly. One is the emergence of a large number of new business entities. According to the data of MOC show that the third party platform companies have more than 5000, through various platforms to carry out cross-border e-commerce business of foreign trade enterprises have more than 2 million; two is the rapid expansion of the size of the transaction. 2012 national cross-border e-commerce transactions has exceeded $\$ 200$ billion, including cross-border e-commerce retail exports exceeded $\$ 150$ billion, compared with the previous year, an increase of over 30\%, far higher than the same period of China's general trade growth, the development potential is huge; the three is to reduce the threshold for small and medium enterprises engaged in export trade. This can effectively promote many small and medium enterprises to enter the international market of the big stage, enhance the vitality of small and medium enterprises, and drive the business development of small and medium enterprises.

To promote the foreign trade transfer mode, adjust the structure, steady growth, and promote the foreign trade industry upgrade and development of green trade, 2014 May 14th Beijing Municipal cross-border e-commerce promote cross-border electronic commerce and public information platform to start the press conference. Embodiment of the Beijing Municipal Commission of Commerce to develop the last part puts forward three security measures to boost Beijing's development of cross-border e-commerce.

\subsection{Comply with the Integration of the Beijing-Tianjin-Hebei Region Development Model}

National “Twelfth Five Year Plan” stressed that the eastern region should aim to play an important role in the national economic development and support and create a more international competitiveness in the eastern part of the city group. In the coming period, it is the key period for the formation and development of large urban agglomeration in China. Beijing, Tianjin and Hebei region is one of the three major cities in the eastern part of China. It is one of the most important supporting areas of China's participation in international competition and modernization.

For Beijing, the development of core business, moving out of the non core business, Beijing-Tianjin-Hebei regional cooperation development is the trend. Amazon China has moved to Wuqing Tianjin district which is the best proof of this development trend.

\subsection{New Terminal Logistics Pattern Emerge in Endlessly}

As the capital of Beijing, electricity suppliers business development in the forefront of the country, natural electricity suppliers logistics business is also soaring. The last mile problem of electricity suppliers gradually highlights, based on the campus, community and other $\mathrm{O} 2 \mathrm{O}$ terminal logistics distribution mode is developing rapidly, and various models are emerging, which has become the important development direction of urban logistics in the new period.

\section{Urban Common Distribution Mode to Strengthen}

Common distribution is the product of low carbon economy. In view of the high cost of logistics, logistics link messy cumbersome problem, Beijing joint distribution of pilot project "100 cities” in the government's leading arises at the historic moment. City common distribution not only optimize the allocation of resources, but also ${ }^{4}$ www.100EC.cn: http://www.100ec.cn/detail--6157257.html 
enhance the customer experience, is the current situation of the electricity suppliers terminal logistics a development trend.

\section{Countermeasures and Suggestions for the Development of E-Commerce Logistics in Beijing}

According to the present situation, problems and trend analysis of e-commerce and logistics development in Beijing, the following countermeasures are put forward for the development of e-commerce logistics in Beijing.

\subsection{Beijing, Tianjin and Hebei Integrated Collaborative Development Model}

Beijing-Tianjin-Hebei area includes two municipalities directly under the central government in Beijing, Tianjin and Tangshan in Hebei province, Baoding, Langfang, Qinhuangdao, Zhangjiakou, Chengde, Cangzhou, Shijiazhuang, Handan, Xingtai, Hengshui and 11 each level city. Those cities are China's most important political and cultural center and also in north China's largest and highest level of development of the economic core area. According to the overall requirements of the capital economic and social development strategy, this area has become an important support area for the construction of international metropolis. Due to the lack of coordination of operational management, and the impact of lagging behind other factors, such as the integration of Beijing, Tianjin and logistics model has not been a good development, as follows:

\subsubsection{Information, Data Center, Logistics Center Edge}

Major electricity suppliers can take the distribution center to move out of Beijing and move into other areas of Beijing, Tianjin and other areas of the way to ease traffic in Beijing city and other issues while the data center is still set up in Beijing. Thus this lays the information center of Beijing City and promotes the development of related areas to achieve a win-win situation.

\subsubsection{Intercity Rail Transit}

Planning of Beijing-Tianjin-Hebei ten tri-cities inter-city railway "public transport", implements the separation of passenger and cargo, which supplies free flow between places.

\subsubsection{Logistics Policy Integration}

Beijing, Tianjin and three to develop a shared interest in the development of regional logistics policy, a win-win development of regional logistics policy, and take full account of the advantages of the three and achieve complementary advantages. Doing those aiming to achieve resource sharing and common development.

\subsubsection{Multi Level Coordination Mechanism}

I advice to establish a central coordination, local leadership, the association to promote, business participation in the regional logistics multi-level cooperation mechanism in Beijing-Tianjin-Hebei region.

\subsection{E-Commerce Logistics Operation Mode of Beijing City}

\subsubsection{Vigorously Promote the Community Logistics Model}

Community will become a new form of consumer market. Community service demand and the increase of the demand for online shopping, making the future demand for community logistics will continue to surge. Communities all over the city, the layout of the stability, should be led by the government to promote the development of community logistics model. The government should vigorously carry out community and property combination, community and convenience stores combined with a variety of new community service station, such as community service stations and other new community logistics mode, ease the last mile electricity supplier distribution pressure, improve community service experience [2].

\subsubsection{Actively Carry out 020 Logistics Mode}

We should actively carry out a variety of O2O logistics mode, including the third party payment platform model, the convenience store $\mathrm{O} 2 \mathrm{O}$ model, intelligent delivery system model and the network model, etc.. Multi level, multi angle $\mathrm{O} 2 \mathrm{O}$ logistics mode is integrate into the electronic commerce terminal logistics. The model is con- 
ducive to enhance the user experience, is conducive to improving the speed of the express response, is conducive to improve the sales and brand awareness, etc.

\subsubsection{Terminal Distribution Station Is the Closest to the Customer End, the Most Able to Understand the Extent of Customer Service End}

What we should do is to strengthen the construction of terminal distribution site and make the end cover more comprehensive, the last 100 meters service more accurate, higher satisfaction.

\section{Beijing E-Commerce Logistics Policy Recommendations}

To develop the e-commerce logistics in Beijing City, it also needs the strong support of the relevant government policies to solve the problems in the practical operation. I suggest that the relevant policies should be set to address the following issues:

\subsection{Electricity Suppliers Intercity Transportation and Tail Number Limit Number Problem}

In the pattern to carry out the integration of the Beijing-Tianjin-Hebei region, and inter-city traffic toll will no doubt become a major factor hindering the development of the pattern. The government should introduce policies to reduce the part of the inter city transportation charges, the implementation of hierarchical policies, the distinction between treatment. In addition, due to the characteristics of a wide range of distribution vehicles, the number of distribution vehicles will become another thorny issue, and the government should deal with the class of vehicles to be treated differently, the lifting of the ban limit, making the use of resources to maximize [3].

\subsection{The Tax Burden to Be Reduced}

The tax expenditure of the logistics enterprises is mainly in three aspects. The first is in providing services sectors, involving value-added tax, business tax, urban maintenance and construction tax, education surcharge and stamp tax. The second is the benefit realizion link, involving enterprise income tax and individual income tax. The third is the service facilities hold and used the links, involving the vehicle purchase tax, property tax, urban land using tax, travel tax, farmland occupation tax, land value-added tax and taxes.

In recent years, the tax revenue of logistics enterprises is in rapid growth. China Federation of logistics \& purchasing and China society of logistics survey tax expenditure statistics of 927 Sample logistics enterprises from 2008 to 2012 years. The tax expenses of sample logistics enterprises on average increased by $9.81 \%$ in 2008-2012 years, compared with the same period operating income and profit increased by $4.56 \%$ and 3.29\% respectively. Compared with the calculation, the growth in revenue and operating income and operating profit were 5.25 and 6.52 percentage points higher than the growth rate of the same period operating income and operating profit.

Tax burden is a major factor in the development of electricity suppliers and logistics development. The government should reduce the burden on the parties from the tax burden. Only reasonable taxes will make the logistics industry in Beijing electric power industry healthy development.

\subsection{Distribution Point Business License to Consider}

General business operations are required to issue a business license. However, the business license application requires a lot of conditions, and the cost of the problem. For the current strong support for $\mathrm{O} 2 \mathrm{O}$ and other logistics mode, often take a small convenience store, etc., for business license is bound to seriously impede the mode of propulsion, and unreasonable. Therefore, the government should introduce relevant policies to support the business license for the class.

\subsection{Big Data Centers to Control}

Beijing, Tianjin and integration of the development model is designed to achieve three complementary advantages. Distribution centers' migration does not mean that the core is also migrated. Beijing should become a big data center across the development model, and the government should introduce policies to ensure that the status 
of Beijing information data center, only in Beijing to play its guiding role.

\subsection{New Logistics Companies Need to Cultivate}

At present, there are many logistics companies only Beijing normal just-in-time. This did not coordinate with increasingly increment distribution business. Other small logistics companies do not become a scale. To assume such a large number of electricity supplier distribution business, Beijing need to develop more large logistics companies. The government should introduce relevant policies to support the cultivation of new logistics companies, the government led, business model, in order to ensure the logistics capacity of Beijing city.

\subsection{Cross-Border Electricity Suppliers Need to Support}

Based on the advantage of the airport area, and Beijing international metropolis of the mark, and the current cross-border business development momentum, Beijing should take advantage of the favorable situation vigorously and should support the development of cross-border e-commerce.

\section{Acknowledgements}

The fund project, Beijing philosophy and social science research base specially commissioned project planning "Research on the development strategy of e-commerce logistics in Beijing" (13JDJGD013).

\section{References}

[1] Yang, Y. and Li, X.H. (2014) Japan’s Developing Experiences in E-Commerce Logistics and the Inspiration on China. China Business and Market, 28, 34-39.

[2] Guo, K. and He, M.K. (2015) Study on Preference of Self-developed or Third Party Logistics of E-commerce Retail Enterprises. Logistics Technology, 34, 126-129.

[3] Dai, J., Jia, Q. and Wang, J. (2014) Study on Influence Factors of Customer Satisfaction in Logistics Distribution Services under B2C E-commerce Environment. Logistics Technology, 9, 166-170. 